(2) Open Access Full Text Article

CASE SERIES

\title{
Invasive atypical thymic carcinoid: three case reports and literature review
}

\author{
This article was published in the following Dove Press journal: \\ OncoTargets and Therapy \\ II October 2016 \\ Number of times this article has been viewed
}

\author{
Shan Zhu',2 \\ Zhong-Tang Wang ${ }^{2}$ \\ Wen-Zhi Liu's,3 \\ Shi-Xiang Zong ${ }^{4}$ \\ Bao-Sheng $\mathrm{Li}^{2}$
}

'School of Medicine and Life Sciences, University of Jinan-Shandong Academy of Medical Sciences, ${ }^{2}$ Department of Radiotherapy, Shandong Cancer Hospital Affiliated to Shandong University, Jinan, ${ }^{3}$ Department of Clinical Oncology, Taian Central Hospital, Taian, ${ }^{4}$ Jinan Hospital, Jinan, Shandong Province, People's Republic of China
Correspondence: Bao-Sheng Li Department of Radiotherapy, Shandong Cancer Hospital Affiliated to Shandong University, Jiyan Road 440, Jinan, 250II7, Shandong Province, People's Republic of China

Tel +8653 I 67626161

Fax +8653167626161

Email baoshli1963@I63.com

\begin{abstract}
Atypical thymic carcinoid is an extremely rare thymic neuroendocrine tumor derived from the neuroendocrine system. The aims of this paper were to investigate the clinical features of atypical thymic carcinoid and collate information and experience to improve the diagnosis and treatment of this disease. We describe three cases of atypical carcinoid of the thymus; clinical features, pathological data, treatment modalities, and short-term patient outcomes were summarized and analyzed. The initial clinical symptoms and signs of all three patients were nonspecific and an anterior mediastinal mass was found in each patient on chest computed tomography scan. All three patients underwent surgical resection (total thymectomy and complete excision of the tumor), followed by postoperative radiotherapy, with or without chemotherapy. The diagnoses of three patients were confirmed by pathological and immunohistochemical evaluation. We also present a review of the literature to collate as much information as possible and provide a reference for proper diagnosis and treatment of atypical thyroid carcinoid.
\end{abstract}

Keywords: thymic tumors, neuroendocrine tumor, carcinoid, atypical carcinoid, atypical thymic carcinoid

\section{Introduction}

Thymic neuroendocrine tumors were first described by Rosai and Higa. ${ }^{1}$ The total number of the reported cases internationally to date is $\sim 400^{2}$ and atypical thymic carcinoid represents an extremely rare group among these with an annual incidence of $\sim 0.18$ per $1,000,000$ population. ${ }^{3}$ The total number of atypical thymic carcinoid cases reported internationally to date is just over $100 .{ }^{4}$ Patients with atypical thymic carcinoid usually present with nonspecific symptoms and approximately half of the cases have no obvious clinical manifestations. ${ }^{5}$ These characteristics reduce the likelihood that patients will seek medical attention at an early stage, and such tumors may even initially escape detection, due to their location. However, atypical thymic carcinoid tumors tend to have an aggressive clinical course. These neoplasms exhibit local recurrence or distant metastasis in $\sim 20 \%-30 \%$ of patients, ${ }^{6}$ and previously reported overall 5-year survival rates range from $56 \%$ to $77 \%{ }^{7}$ In order to improve the effectiveness of the treatment of patients with atypical thymic carcinoid, it is essential that clinicians are able to recognize these tumors. In this report, we describe three cases which offer insights valuable for future study of atypical thymic carcinoid.

\section{Case reports}

Three cases of atypical thymic carcinoid tumor were collected from the department of thoracic surgery of our hospital from 1999 to 2015 . All subjects gave written informed consent to have their data/images published in this report. The study was approved by the Ethical Committee of Shandong Cancer Hospital. 


\section{Case I}

A 37-year-old male patient was hospitalized as a result of the discovery of an anterior mediastinal mass during physical examination in 2012 at another hospital. Mediastinal tumor resection was performed and a diagnosis of atypical thymic carcinoid tumor was made, based on histological evaluation. After the first operation, case 1 underwent six cycles of chemotherapy consisting of docetaxel $\left(60 \mathrm{mg} / \mathrm{m}^{2}\right.$ on day 1 and $80 \mathrm{mg} / \mathrm{m}^{2}$ on day 8$)$ and cisplatin $\left(60 \mathrm{mg} / \mathrm{m}^{2}\right.$ on days 1 and 2).

Two years later, the patient was readmitted to our hospital due to chest pain, and relapsing masses were found. Physical examinations were normal. The patient had a history of smoking for more than 10 years. He did not have a previous history of long-term medication or of exposure to chemicals, smog, or dust, a family genetic history, or a history of cancer. A routine blood test was normal, and laboratory tests revealed normal liver and kidney functions. The total serum calcium level was $2.90 \mathrm{mmol} / \mathrm{L}$ (normal range, 2.03-2.54 mmol/L). The serum tumor marker levels were as follows: neuron-specific enolase (NSE) was $15.19 \mathrm{ng} / \mathrm{mL}$ (normal $<17 \mathrm{ng} / \mathrm{mL}$ ). Computed tomography (CT) scans of the chest revealed an anterior mediastinal mass of $1.8 \mathrm{~cm}$ in the greatest dimension. Thymectomy was performed for this case, with partial resection of the surrounding tissues, as described in Table 1. Postoperative pathological analysis confirmed the diagnosis of atypical carcinoid, Masaoka stage III. ${ }^{8}$ After the second operation, case 1 underwent adjuvant radiation therapy (50 Gy/25 f) and chemotherapy (VIP protocol: ifosfamide intravenous drip on days $1-5$, cisplatin $40 \mathrm{mg}$ intravenous drip on days $1-4$, and etoposide $100 \mathrm{mg}$ intravenous drip on days 1-6; the protocol was repeated once every 3 weeks, and a total of four cycles were administered). The response to the therapy of case 1 was evaluated as complete response. Adverse events related to radiotherapy and chemotherapy in case 1 were grade 1 in the gastrointestinal system and grade 2 in the bone marrow.

\section{Case 2}

A 75-year-old male patient was admitted to our hospital in August 2015 with complaints of chest tightness and discomfort while climbing stairs. Physical examinations were normal. Laboratory test results were similar to those of case 1 . The total serum calcium level was $2.50 \mathrm{mmol} / \mathrm{L}$ and NSE was $13.69 \mathrm{ng} / \mathrm{mL}$. A CT scan revealed an anterior mediastinal mass measuring $4.5 \mathrm{~cm}$ in the greatest dimension. Thoracoscopic tumor resection and right upper lobe wedge resection were performed. After the operation, only radiotherapy was administered at the same radiation dose as described for case 1, as the patient refused to accept chemotherapy. The response to radiotherapy was evaluated as complete response.

\section{Case 3}

A 55-year-old male patient was admitted to our hospital in October 2015 because an anterior mediastinal mass was found during a routine physical examination. There were no associated complaints of hemoptysis, cough, chest pain, or any significant past medical or surgical history. Laboratory tests results were as follows: total serum calcium level $2.53 \mathrm{mmol} / \mathrm{L}$ and NSE $19.27 \mathrm{ng} / \mathrm{mL}$. Radiological investigations revealed a mediastinal mass measuring $8 \mathrm{~cm}$ in its largest dimension (Figure 1). Thymectomy was performed for this case, along with sternotomy mediastinal tumor resection and left upper lobe wedge resection. The administration of adjunctive therapy was the same as that for case 2 .

\section{Pathological findings}

Although the dimensions of the gross tumor specimens were quite different in the three cases, at $18 \times 18 \times 10,42 \times 38 \times 45$,

Table I Summary of three cases of atypical thymic carcinoid

\begin{tabular}{|c|c|c|c|c|c|c|c|c|}
\hline Case & Sex & Age & Symptoms & Tumor size & Invasion & Surgery & $\begin{array}{l}\text { Postoperative } \\
\text { treatment }\end{array}$ & Prognosis \\
\hline I & Male & 37 & $\begin{array}{l}\text { Occasional chest } \\
\text { discomfort } \\
\text { and pain }\end{array}$ & $42 \times 38 \times 45 \mathrm{~mm}^{3}$ & $\begin{array}{l}\text { Invasion of surrounding } \\
\text { fat tissue, cancer embolus } \\
\text { formation in veins, and } \\
\text { lymph node metastasis ( } / / \mathrm{I})\end{array}$ & $\begin{array}{l}\text { Transsternal } \\
\text { thymectomy }\end{array}$ & $\begin{array}{l}\text { Postoperative } \\
\text { concurrent } \\
\text { chemoradiotherapy }\end{array}$ & $\begin{array}{l}\text { Bone metastasis } \\
5 \text { months after } \\
\text { the second } \\
\text { operation }\end{array}$ \\
\hline 2 & Male & 75 & $\begin{array}{l}\text { Chest tightness } \\
\text { and discomfort } \\
\text { while climbing } \\
\text { stairs }\end{array}$ & $18 \times 18 \times 10 \mathrm{~mm}^{3}$ & $\begin{array}{l}\text { Invasion of surrounding fat } \\
\text { tissue and lung }\end{array}$ & $\begin{array}{l}\text { Thoracoscopic tumor } \\
\text { resection and right } \\
\text { upper lobe wedge } \\
\text { resection }\end{array}$ & $\begin{array}{l}\text { Postoperative } \\
\text { radiotherapy }\end{array}$ & $\begin{array}{l}\text { Event-free } \\
\text { survival }\end{array}$ \\
\hline 3 & Male & 55 & Asymptomatic & $57 \times 79 \times 54 \mathrm{~mm}^{3}$ & $\begin{array}{l}\text { Invasion of surrounding fat } \\
\text { tissue }\end{array}$ & $\begin{array}{l}\text { Sternotomy mediastinal } \\
\text { tumor resection and } \\
\text { left upper lobe wedge } \\
\text { resection }\end{array}$ & $\begin{array}{l}\text { Postoperative } \\
\text { radiotherapy }\end{array}$ & $\begin{array}{l}\text { Event-free } \\
\text { survival }\end{array}$ \\
\hline
\end{tabular}




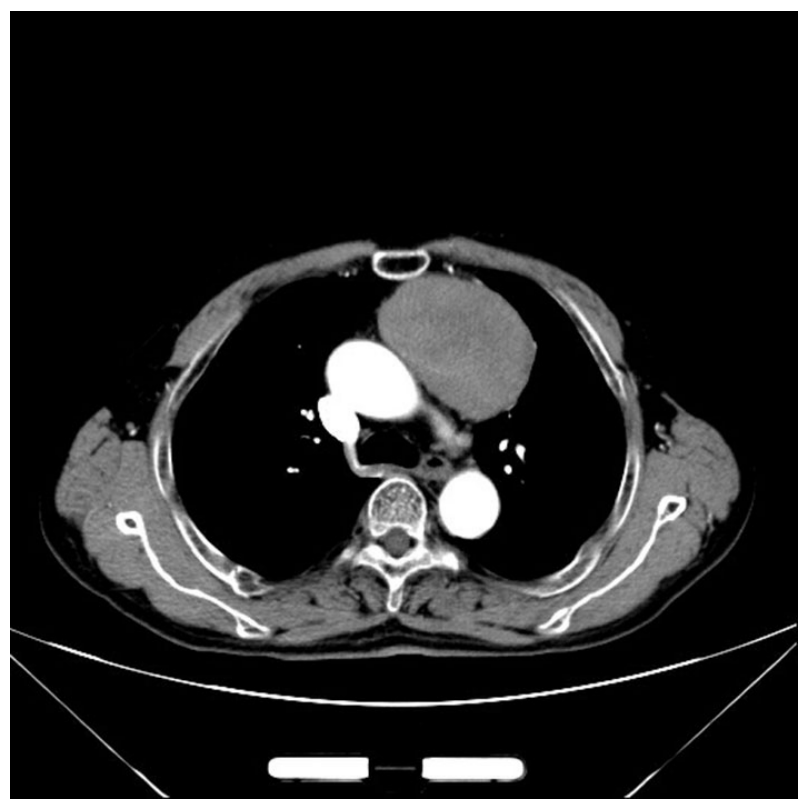

Figure I Computed tomography scan of case 3.

Note: An irregular mass with a clear border, uneven density, and heterogeneous enhancement is visible.

and $57 \times 79 \times 54 \mathrm{~mm}$ for cases 1,2 , and 3 , respectively, the microscopic features were quite similar. Hematoxylin-eosin staining demonstrated that the tumor cells were arranged in a nested, trabecular, or pseudorosette pattern, with mild atypia and homogeneous staining in nuclei and chromatin in all three cases (Figure 2). Immunohistochemistry of tumor samples of the three cases demonstrated positivity for CD56, CAM5.2, $\mathrm{CgA}, \mathrm{CK}$, and Syn (Figure 3A-E), and staining indices for Ki- 67 of between $5 \%$ and 20\% (Figure 3F). Three identified tumors were at stage III during presentation.

For case 1, recurrence occurred 2 years after the first operation, and bone metastasis was found 5 months after

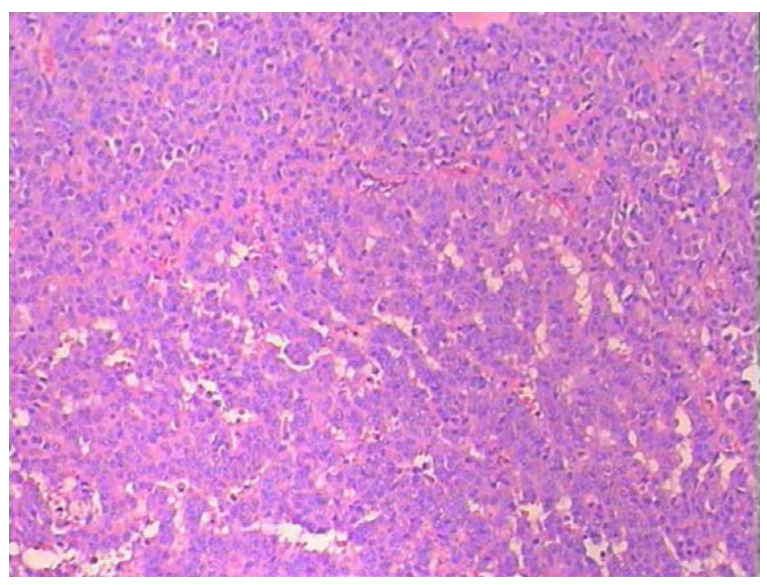

Figure 2 Pathological results from an atypical thymic carcinoid.

Notes: A section of the mass from case 3 was observed under a light microscope (Olympus BX51; Olympus Corporation, Tokyo, Japan) after hematoxylin-eosin staining. Original magnification $\times 100$. case 1 underwent the second operation and treatment. Cases 2 and 3 are currently free of recurrence, while case 1 is also alive with a recurrent tumor. Detailed information for the three patients is summarized in Table 1 .

\section{Discussion}

Atypical thymic carcinoid is a rare type of thymic neuroendocrine tumor, and approximately one-third of patients with atypical thymic carcinoid tumors are asymptomatic; ${ }^{2}$ therefore, the detailed clinical features of these tumors are not well defined. This hinders accurate diagnosis of the disease at an early stage, which is essential to ensure prompt treatment, given the poorer prognosis of atypical thymic carcinoid tumors compared with benign tumors of the thymus.

\section{Classification and clinical manifestations}

Thymic neuroendocrine tumors are malignant tumors originating from neuroendocrine cells, which are diffusely distributed in tissues and organs. Based on histological features and the degree of malignancy, such tumors can be divided into four types: typical carcinoid, atypical carcinoid, large cell neuroendocrine tumor, and small cell neuroendocrine tumor. ${ }^{9}$ The disease is more common in men than in women, ${ }^{10-12}$ with an average age at diagnosis ranging from 42.0 to 56.5 years. ${ }^{11,13,14}$ The three cases of atypical thymic carcinoid tumors reported in this paper were male, with an average age of 55.7 years, which is consistent with the literature.

Atypical carcinoid tumor is characterized by a high degree of malignancy and invasiveness without specific clinical features; however, as approximately one-third of patients have no obvious early symptoms and are identified during routine physical examination due to the discovery of an anterior mediastinal mass, the disease is generally already at an advanced stage at diagnosis. The remaining two-third of patients have nonspecific symptoms, which mainly manifest as cough, chest pain, breathing difficulties, and other symptoms related to the anterior mediastinal space-occupying lesions, making it unlikely that patients will receive medical attention at an early stage. In addition, these tumors may produce ectopic hormones, such as serotonin, leading to carcinoid syndrome in $\sim 2 \%$ of patients. ${ }^{15}$ Ectopic production of adrenocorticotropic hormone, similar to that associated with Cushing's syndrome, is present in $\sim 25 \%$ of patients, and $\sim 15 \%$ of patients present with multiple endocrine neoplasia type 1 , a syndrome associated with thymic carcinoid tumors. ${ }^{16}$ In $\sim 20 \%-40 \%$ of patients with atypical carcinoid tumor of the thymus, the tumor exhibits invasion of the chest wall, lung, liver, brain, or other organs. ${ }^{17}$ In the three cases reported in this paper, two cases had chest discomfort and one had no symptoms. All identified 

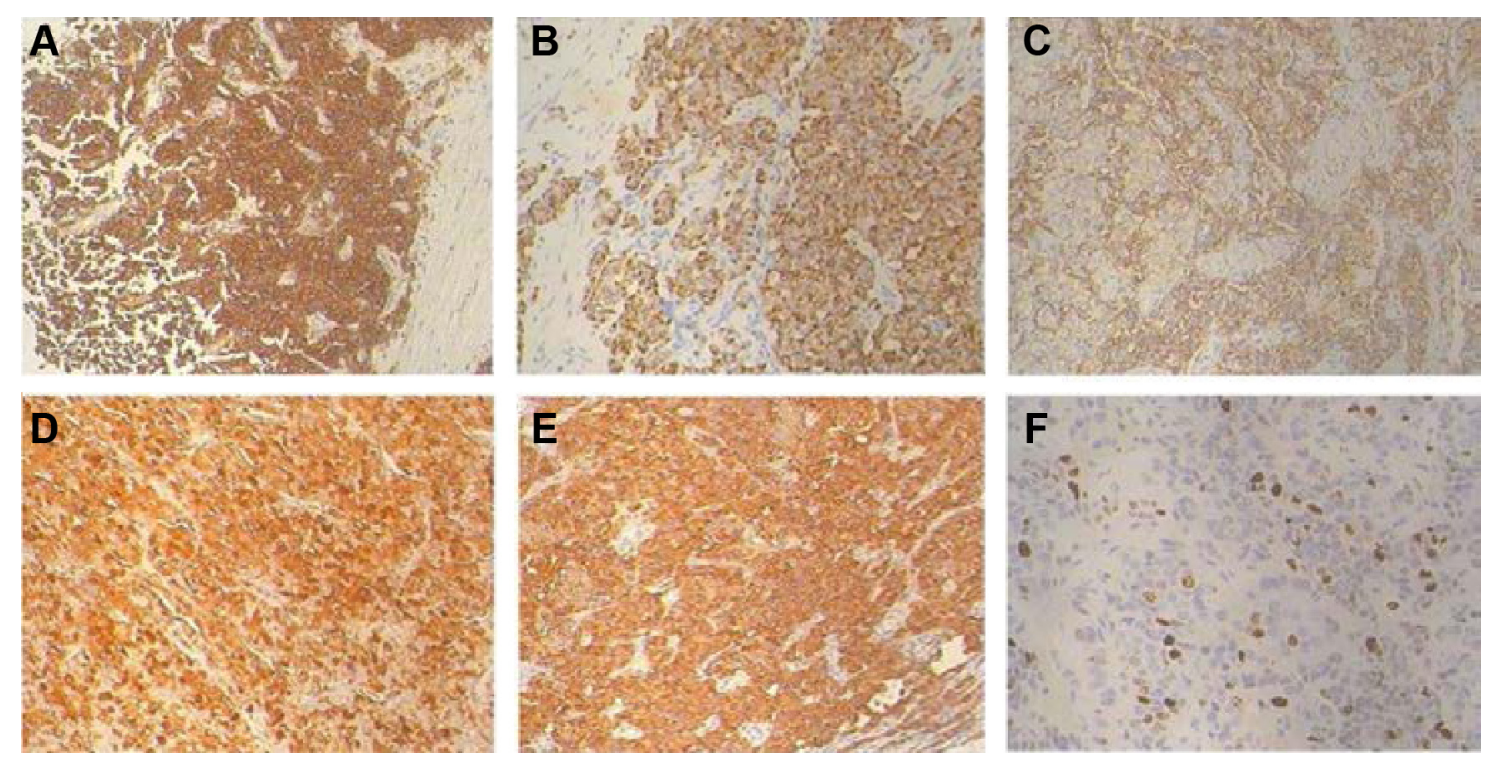

Figure 3 Immunohistochemistry results from an atypical thymic carcinoid.

Notes: Immunohistochemistry analysis of a tumor sample from case 3 demonstrating positive detection of CD56, CAM5.2, CgA, CK, and Syn (A-E, respectively). The staining index for Ki-67 (F) was between $5 \%$ and $20 \%$. Magnification $\times 100$.

tumors were at stage III during presentation, confirming the highly aggressive biological behavior of these neoplasms.

\section{Diagnostic examinations}

Diagnostic imaging examinations lack specificity for the diagnosis of atypical carcinoid tumors of the thymus. According to National Comprehensive Cancer Network guidelines, CT scanning with contrast is the initial imaging modality of choice; positron emission tomography-CT is optional for the diagnosis of atypical carcinoid tumor of the thymus; and magnetic resonance imaging can also be used as clinically indicated. The following findings on CT images may suggest atypical carcinoid tumor of the thymus: 1) a large mass with an irregular or lobulated shape in the mediastinum close to blood vessels or surrounding pericardium and 2) uniform or nonuniform density in plain scan, mild to moderate heterogeneous enhancement in enhanced scan, immature blood vessels, and liquefied necrotic area within the tumor. With the technical advances in multislice spiral CT, the application of magnetic resonance imaging for thymic tumor assessment has gradually reduced. For patients who have a contraindication to iodine contrast agent, magnetic resonance imaging can be used to evaluate the local invasion of the tumor. Although the $\mathrm{CT}$ findings in the three cases in this report were consistent with the literature, the diagnosis of atypical carcinoid tumor could not be made without final confirmation by histological evaluation.

The diagnosis of atypical carcinoid tumor of the thymus mainly relies on pathological examination. Macroscopically, early-stage tumors are typically smooth and round, while advanced tumors are irregular in shape with calcification. Microscopically, typical carcinoid of the thymus is well differentiated, with little necrosis and a mitotic index $<2 / 10$ high-power fields (HPF); atypical carcinoid tumor of the thymus is rarer, and well differentiated, with a mitotic index $\geq 2 / 10$ HPF; poorly differentiated neuroendocrine tumors of the thymus with a mitotic index $>2 / 10$ HPF can be further divided into small cell, or large cell, neuroendocrine tumors, based on cell morphology. The diagnosis of atypical carcinoid tumor of the thymus is usually confirmed by immunohistochemistry, this knowledge may assist to formulate a proper differential diagnosis. ${ }^{14}$ The World Health Organization has defined such tumors as those with strong and diffuse expression, usually of more than one of the four neuroendocrine markers chromogranin A, synaptophysin, CD56, and NSE in more than $50 \%$ of tumor cells. ${ }^{18} \mathrm{Ki}-67$ index is also used as the index to discern tumor may be the high or low malignancy of tumor. Ki-67 index between $0 \%$ and $2 \%$ is known as G1 phase; the index between $2 \%$ and $20 \%$, G2 phase; and the index between $20 \%$ and $100 \%$, G3 phase. The phases G1, G2, and G3 mean well differentiated, middle differentiated, and poorly differentiated, respectively.

The diagnosis of atypical carcinoid tumor of the thymus in three cases in this report with anterior mediastinal masses was confirmed by postoperative pathological evaluation.

\section{Differential diagnosis}

The diagnosis of atypical carcinoid tumor of the thymus is implied by excluding other diagnoses. For patients with 
anterior mediastinal lesions, the differential diagnosis of the lesions includes all kinds of primary mediastinal tumors, principally lymphoma, germ cell tumors, parathyroid adenoma or carcinoma, pericardial cysts, thymoma, and metastatic tumors with other origins. Thymic tumors account for $\sim 47 \%$ of anterior mediastinal tumors, including thymoma, thymic carcinoma, thymiccysts, lipomas, and thymic neuroendocrine tumors.

\section{Treatment}

First, early surgery is critical for the treatment of patients with atypical carcinoid tumor of the thymus, as it has been suggested by the World Health Organization that this disease has a high malignant potential at all stages. Indeed, it has been reported that the prognosis of patients whose tumors have been completely resected was better than that of patients whose tumors could not be completely removed. ${ }^{19}$ Rea et al found that the long-term survival (mean 23.8 months) of patients with complete excision is $81.8 \%$ while that of patients without complete excision is only $9.1 \% .^{20}$ Weksler reported a 5-year survival rate of $58 \%$ in patients who underwent surgical resection versus $26 \%$ in patients who did not accept surgery. ${ }^{21}$ Second, for unresectable or metastatic tumors, the National Comprehensive Cancer Network guidelines recommend chemotherapy with or without radiation therapy. Tiffet et al also recommended adjuvant radiotherapy and/or chemotherapy for improved outcomes (no recurrence or distant metastasis). ${ }^{4}$ Okuma et al found that S-1 for thymic carcinoma achieved an $85 \%$ disease control rate. ${ }^{22}$ In contrast, Gaur ${ }^{11}$ and Cardillo ${ }^{19}$ reported a detrimental effect of radiotherapy for those patients who received it versus those who did not, and there was no survival benefit for radiotherapy. Definitive determination of whether the treatment is beneficial for patient survival awaits further studies; however, we believe that chemotherapy and radiotherapy are worth pursuing. Platinum-containing protocols, such as cisplatin and etoposide or taxol and cisplatin can be used for chemotherapy. With regard to radiotherapy, the radiation dose recommended by National Comprehensive Cancer Network guidelines (2015) is as follows:

1. A dose of 1.8-2.0 Gy per daily fraction is applied with conventional fractionation.

2. A dose of 60-70 Gy should be given to patients with unresectable disease.

3. For adjuvant treatment, the radiation dose consists of 45-50 Gy for clear/close margins and 54 Gy for microscopically positive resection margins. A total dose of 60 Gy and above should be given to patients with gross residual disease (similar to patients with unresectable disease).

In summary, almost every author stresses that complete surgical excision is the treatment of choice for thymic carcinoid. Adjuvant chemoradiation requires further study.

In addition to chemotherapy and radiotherapy, other therapeutic strategies have been reported. For example, Lausi et al found that tyrosine kinase inhibitors, vascular endothelial growth factor receptor inhibitors, somatostatin, histone deacetylase inhibitors, DNA methyltransferase inhibitor, cyclin-dependent, and tropomyosin globulin inhibitors may also be beneficial in the treatment of thymic carcinoid. ${ }^{23}$ Hamada et al report a case positive for CD117 (KIT) with a good clinical response (no local recurrence or distant metastasis) to imatinibmesylate. ${ }^{24}$

The postoperative treatment strategy for the three cases with atypical carcinoid tumor of thymus at stage III reported in this paper was consistent with the literature.

\section{Prognosis}

Patients with thymic neuroendocrine tumors have a poor prognosis. Even after radical treatment, the overall 5-year survival rate is only $30 \%-70 \%{ }^{3,4,7}$ Even though atypical carcinoid tumors of the thymus belong to the group of well differentiated, among these, the overall 5-year survival rate is $56 \%-77 \%{ }^{7}$ and the overall 10 -year survival rate is $30 \%{ }^{25}$ This is because of the aggressive nature of atypical carcinoid tumors that have high rates of recurrence and metastasis. Unfortunately, the follow-up time for the three cases presented in this report is too short to provide reliable prognostic information.

In conclusion, atypical carcinoid tumor of the thymus has the following features: it occurs more frequently in males than in females, the preoperative diagnosis is difficult, it has a high degree of malignancy and a high rate of metastasis, and postoperative survival rate is relatively low. As the prevalence of the disease is extremely low, prospective studies are not possible; therefore, treatment and diagnostic guidelines for the disease could be based on systemic retrospective studies containing a small number of cases.

\section{Acknowledgment}

The authors specially thank Professor Dexian Zhang (Department of Pathology, Shandong Cancer Hospital Affiliated to Shandong University) for his help with the revision of the manuscript.

\section{Disclosure}

The authors report no conflicts of interest in this work. 


\section{References}

1. Rosai J, Higa E. Mediastinal endocrine neoplasm, of probable thymic origin, related to carcinoid tumor. Clinicopathologic study of 8 cases. Cancer. 1972;29(4):1061-1074.

2. Filosso P L, Yao X, Ahmad U, et al. Outcome of primary neuroendocrine tumors of the thymus: a joint analysis of the International Thymic Malignancy Interest Group and the European Society of Thoracic Surgeons databases. J Thorac Cardiovasc Surg. 2015;149(1):103e2-109e2.

3. Öberg K, Hellman P, Ferolla P, et al. Neuroendocrine bronchial and thymic tumors: ESMO Clinical Practice Guidelines for diagnosis, treatment and follow-up. Ann Oncol. 2012;23(suppl 7):vii120-vii123.

4. Tiffet O, Nicholson AG, Ladas G, Sheppard MN, Goldstraw P. A clinicopathologic study of 12 neuroendocrine tumors arising in the thymus. Chest. 2003;124(1):141-146.

5. Arora R, Gupta R, Sharma A, et al. Primary neuroendocrine carcinoma of thymus: a rare cause of cushing's syndrome. Indian J Pathol Microbiol. 2010;53(1):148.

6. Moran CA, Suster S. Neuroendocrine carcinomas (carcinoid tumor) of the thymus. Am J Clin Pathol. 2000;114(1):100-110.

7. Han B, Sun JM, Ahn JS, Park K, Ahn MJ. Clinical outcomes of atypical carcinoid tumors of the lung and thymus: 7-year experience of a rare malignancy at single institute. MedOncol. 2013;30(1):1-7.

8. Ruffini E, Filosso PL, Mossetti C, et al. Thymoma: inter-relationships among World Health Organization histology, Masaoka staging and myasthenia gravis and their independent prognostic significant a singlecentre experience. Eur J Cardio-Thorac Surg. 2011;40(1):146-153.

9. Travis WD, Rush W, Flieder DB, et al. Survival analysis of 200 pulmonary neuroendocrine tumors with clarification of criteria for atypical carcinoid and its separation from typical carcinoid. Am J Surg Pathol. 1998,22(8):934-944.

10. Soga J, Yakuwa Y, Osaka M. Evaluation of 342 cases of mediastinal/ thymic carcinoids collected from literature: a comparative study between typical carcinoids and atypical varieties. Ann Thorac Cardiovasc Surg. 1999;5(5):285-292.

11. Gaur P, Leary C, Yao JC. Thymic neuroendocrine tumors: a SEER database analysis of 160 patients. Ann Surg. 2010;251(6):1117-1121.

12. Crona J, Björklund P, Welin S, Kozlovacki G, Oberg K, Granberg D. Treatment, prognostic markers and survival in thymic neuroendocrine tumours. A study from a single tertiary referral centre. Lung Cancer. 2013; 79(3):289-293.
13. Chaer R, Massad MG, Evans A, Snow NJ, Geha AS. Primary neuroendocrine tumors of the thymus. Ann Thorac Surg. 2002;74(5): $1733-1740$.

14. Hage R, de la Rivière AB, Seldenrijk CA, van den Bosch JM. Update in pulmonary carcinoid tumors: a review article. Ann Surg Oncol. 2003; 10(6):697-704.

15. Gal AA, Kornstein MJ, Cohen C, Duarte IG, Miller JI, Mansour KA. Neuroendocrine tumors of the thymus: a clinicopathological and prognostic study. The Ann Thorac Surg. 2001;72(4):1179-1182.

16. Lin FCF, Lin CM, Hsieh CC, Li WY, Wang LS. Atypical thymic carcinoid and malignant somatostatinoma in type I multiple endocrine neoplasia syndrome: case report. Am J Clin Oncol. 2003;26(3):270-272.

17. Weissferdt A, Moran CA. Thymomas with prominent glandular differentiation: a clinicopathologic and immunohistochemical study of 12 cases. Hum Pathol. 2013;44(8):1612-1616.

18. Marx A, Chan JKC, Coindre JM, et al. The 2015 World Health Organization classification of tumors of the thymus: continuity and changes. $J$ Thorac Oncol. 2015;10(10):1383-1395.

19. Cardillo G, Rea F, Lucchi M, et al. Primary neuroendocrine tumors of the thymus: a multicenter experience of 35 patients. Ann Thorac Surg. 2012;94(1):241-246.

20. Rea F, Marulli G, Bortolotti L, Feltracco P, Zuin A, Sartori F. Experience with the "da Vinci" robotic system for thymectomy in patients with myasthenia gravis: report of 33 cases. Ann Thorac Surg. 2006; 81(2):455-459.

21. Weksler B, Dhupar R, Parikh V, Nason KS, Pennathur A, Ferson PF. Thymic carcinoma: a multivariate analysis of factors predictive of survival in 290 patients. Ann Thorac Surg. 2013;95(1):299-303.

22. Okuma Y, Hosomi Y, Miyamoto S, Shibuya M, Okamura T, Hishima T. Correlation between S-1 treatment outcome and expression of biomarkers for refractory thymic carcinoma. BMC Cancer. 2016;16(1):1.

23. Lausi PO, Refai M, Filosso PL, et al. Thymic neuroendocrine tumors. Thorac Surg Clin. 2014;24(3):327-332.

24. Hamada S, Masago K, Mio T, et al. Good clinical response to imatinib mesylate in atypical thymic carcinoid With KIT overexpression. JClin Oncol. 2011;29(1):e9-e10.

25. Ströbel P, Zettl A, Shilo K, et al. Tumor genetics and survival of thymic neuroendocrine neoplasms: a multi-institutional clinicopathologic study. Genes Chromosomes Cancer. 2014;53(9):738-749.
OncoTargets and Therapy

\section{Publish your work in this journal}

OncoTargets and Therapy is an international, peer-reviewed, open access journal focusing on the pathological basis of all cancers, potential targets for therapy and treatment protocols employed to improve the management of cancer patients. The journal also focuses on the impact of management programs and new therapeutic agents and protocols on

\section{Dovepress}

patient perspectives such as quality of life, adherence and satisfaction The manuscript management system is completely online and includes a very quick and fair peer-review system, which is all easy to use. Visit http://www.dovepress.com/testimonials.php to read real quotes from published authors. 